\title{
A AXIOLOGIA DO PLANO DE LOGÍSTICA SUSTENTÁVEL DOS TRIBUNAIS PARAA SOCIEDADE
}

\author{
Daniele De Castro Pessoa De Melo \\ Coordenadora, Professora e Pesquisadora do Mestrado Profissional em Tecnologia Ambiental \\ do Instituto de Tecnologia de Pernambuco (ITEP), Recife-PE, Brasil. Pós-Doutora em \\ Engenharia Química pela Universidade Federal de Pernambuco - UFPE, Doutora em \\ Engenharia Química pela Universidade Federal de Pernambuco - UFPE, Mestra em \\ Engenharia Química pela Universidade Federal de Pernambuco - UFPE e Graduada em \\ Engenharia Química pela Universidade Católica de Pernambuco, Brasil. \\ Email: daniele.castro@itep.br
}

Barbara De Castro Leao

Assessora de Magistrado do Tribunal de Justiça do Estado de Pernambuco (TJPE), Recife-PE, Brasil. Mestra Profissional em Tecnologia Ambiental pelo Instituto de Tecnologia Ambiental (ITEP), Recife-PE, Brasil. Pós-Graduada em Mediação e Arbitragem pela Faculdade de Olinda (FOCCA), Olinda-PE, Brasil. Pós-Graduada em Direito do Trabalho pela Faculdade Internacional de Curitiba (FACINTER), Curitiba-PR, Brasil. MBA em Administração Pública e Gerência de Cidades pela Faculdade Internacional de Curitiba (FACINTER), CuritibaPR, Brasil. Bacharel em Direito pela Faculdade de Olinda (FOCCA), Olinda-PE, Brasil. Tecnóloga em Gestão Pública pela Faculdade de Tecnologia e Ciências de Pernambuco (FATEC), Curitiba-PR, Brasil Email: babileao@bol.com.br

\section{RESUMO}

O objetivo deste artigo consiste em analisar o Plano de Logística Sustentável preconizada no Poder Judiciário brasileiro como política pública eficaz no parâmetro do Estado de Direito Socioambiental. Para isso, foi utilizada a abordagem qualitativa e explicativa pautada em análise de dados bibliográficos advindos de artigos científicos, livros e normas, cujo título ou tema discorrido se tratava de Plano de Logística Sustentável, Estado de Direito Socioambiental, gestão ambiental, sustentabilidade, políticas públicas e/ou o papel do poder judiciário na matéria do meio ambiente. E após uma reflexão teórica sobre a relação entre as diretrizes do Estado de Direito Socioambiental e as políticas públicas sustentáveis do Poder Judiciário, conclui-se que os Tribunais ao adotarem uma gestão socioambiental responsável passa a ser um modelo influenciador para a formação axiológica da sociedade pautada na justiça ambiental, uma vez que há o incentivo do consumo consciente, revela aos servidores sobre a amplitude do conceito da eficiência de suas atividades laborais, o qual também está relacionada com a diminuição dos gastos públicos e dos impactos ambientais, além de proporcionar a conscientização dos servidores sobre a necessidade de ser sustentável no âmbito do Estado de Direito Socioambiental. Por fim, justifica a importância do presente 
estudo pelo fato de a obrigatoriedade do Plano de Logística Sustentável nos Tribunais ter sido regulamentada apenas no ano de 2015, por meio da Resolução do Conselho Nacional de Justiça de $\mathrm{n}^{\circ}$ 201, o que torna um tema recente e de pouca discussão.

Palavras-chave: Gestão socioambiental; Justiça ambiental; Poder Judiciário.

\title{
THE AXIOLOGY OF THE SUSTAINABLE LOGISTICS PLAN OF THE COURTS FOR SOCIETY
}

\begin{abstract}
The objective of this article is to analyze the Sustainable Logistics Plan advocated in the Brazilian Judiciary as an effective public policy in the parameter of the Social and Environmental Law. For that, the qualitative and explanatory approach based on the analysis of bibliographical data from scientific articles, books and standards was used, whose title or theme was a Sustainable Logistics Plan, Socioenvironmental Law State, environmental management, sustainability, public policies and / or the role of the judiciary in environmental matters. And after a theoretical reflection on the relationship between the guidelines of the Socio-environmental Law State and the sustainable public policies of the Judiciary and on the value importance of such measures in society, it is concluded that the Courts by adopting a responsible socio-environmental management becomes an influential model for the axiological formation of the society based on environmental justice, since there is the incentive of conscious consumption, reveals to the employees about the breadth of the concept of the efficiency of their labor activities, which is also related to the decrease of public expenditures and environmental impacts, in addition to providing employees with the awareness of the need to be sustainable within the scope of the Social and Environmental Law. Finally, it justifies the importance of the present study because the obligation of the Sustainable Logistics Plan in the Courts has been regulated only in 2015, through the Resolution of the National Council of Justice of 201, which makes a recent theme and of little discussion.
\end{abstract}

Keywords: Socio-environmental management; Environmental justice; Judicialpower. 


\section{INTRODUÇÃO}

A ideologia primordial para o surgimento do Estado de Direito Socioambiental é a institucionalização da sustentabilidade, pois um governo que insere em seu ordenamento jurídico e, consequentemente, em seus princípios teleológicos de suas atividades governamentais a promoção da sustentabilidade demonstra a preocupação em assegurar efetivamente aos cidadãos o desenvolvimento social, político e econômico sem prejudicar as gerações futuras, tanto em relação aos recursos naturais quanto à qualidade de vida dos indivíduos. Garantir o desenvolvimento sustentável é, portanto, agir com visão protecionista voltada não somente à sociedade atual, mas também àquela em que existirá(BLÁZQUEZ; PERETTI, 2012; MCINTYRE-MILLS et al., 2008).

Então, proteger o meio ambiente e proporcionar a dignidade da pessoa humana são as consequências da concretização do Estado de Direito Socioambiental. E essa decisão no âmbito governamental da escolha da melhor ação voltada à sustentabilidade, fundamentada pela justiça ambiental e pela justiça social, desenvolve uma nova visão dos próprios cidadãos sobre a importância de agir em conformidade com o desenvolvimento que permite o equilíbrio do meio ambiente. A formação axiológica da sociedade vai paulatinamente sendo alicerçada em princípios mais justos para as pessoas e para o meio no qual elas estão inseridas (SARAIVA; VÉRAS NETO, 2012).

Essa construção dos valores sustentáveis permeia pela responsabilidade moral de cada indivíduo, afinal de contas,

As futuras gerações possuem o direito aos bens naturais e a uma natureza preservada. O zelo com o contexto socioambiental pode ser reconhecido e aceito por todos os seres humanos como um interesse comum, ao qual todos vão respeitar de igual forma, induzindo assim a posição original e a busca dos princípios da justiça que levem a cooperação social e a minimização dos impactos e riscos ambientais, permitindo que haja um direito ao meio ambiente, disponível a todos os demais seres humanos (CALGARO; PEREIRA, 2017, p. 286).

Assegurar a proteção ambiental é uma atitude a qual está inserida na ética pública de adequar toda e qualquer atividade estatal ao interesse comum e ao bem-estar da coletividade. E inevitavelmente é por meio das políticas públicas que o Estado atua direta ou indiretamente na 
sociedade para garantir os direitos a que assistem todos. E nessa seara o Poder Judiciário, por fazer parte dessa estrutura do Estado de Direito Socioambiental, também adquire um papel fundamental na transformação da conduta da população. Os Tribunais possuem genuinamente a missão de ser um instrumento efetivo de justiça, de forma célere e ampla, por meio de despachos, decisões e sentenças proferidos nos processos judiciais. Contudo, esse sentido de justiça transcende a um modelo administrativo e estrutural mais adequado e justo também para o meio ambiente.E essa transcendência da justiça para o âmbito sustentável abarca um sentido axiológico, ético e valorativo em si, que abarca não somente a questão formal da justiça, mas também a justiça material, promovendo a noção da razoabilidade dos critérios adotados em uma determinada conduta laboral. Pautada nessa amplitude do significado de justiça, os Tribunais passam a adquirir uma responsabilidade social e ambiental e atuam como formadores de opiniões e como modelos de padrão de conduta para a sociedade, sendo o Plano de Logística Sustentável o marco normativo mais eficaz, que trouxe, inclusive, a homogeneidade dos critérios e do controle das ações sustentáveis a serem adotadas nos Órgãos Judiciários.

E é justamente nesse contexto que o objetivo do presente artigo consiste em analisar o Plano de Logística Sustentável na seara do Poder Judiciário brasileiro como uma política pública eficaz e de carga valorativa para o Estado de Direito Socioambiental e, consequentemente, para a população. Para isso, foi utilizada a abordagem qualitativa e explicativa pautada em análise de dados bibliográficos advindos de artigos científicos, livros e normas. A questão normativa foi direcionada à Resolução $\mathrm{n}^{\circ}$ 201/2015 do Conselho Nacional de Justiça, a qual é um dos pilares deste trabalho, e o Manual da Agenda Ambiental da Administração Pública, e os livros utilizados trazem explanação sobre a gestão pública e questões constitucionais relacionados a políticas ambientais. No tocante aos artigos científicos utilizados, o acervo foi selecionado a partir de buscas por revistas eletrônicas disponibilizadas na rede mundial de computadores, a Internet,sendo em sua maioria periódicos com classificação, na Qualis da Capes,a partir de B2 no campo de ciências ambientais e publicados nos últimos cinco anos,cujo título ou tema discorrido se tratava de Plano de Logística Sustentável, Estado de Direito Socioambiental, gestão ambiental, sustentabilidade, políticas públicas e/ou o papel do poder judiciário na matéria do meio ambiente.

Verifica-se que a temática pesquisada condiz estritamente com o 
assunto deste trabalho e que, a partir de uma reflexão teórica foi analisado: a)o "Estado de Direito Socioambiental e a Gestão Responsável no Poder Público" com uma abordagem das características do Estado Socioambiental, dos direitos difusos de terceira geração como a solidariedade, da instituição da gestão pública socioambiental no governo brasileiro com seus respectivos exemplos, como a Agenda Ambiental na Administração Pública (A3P); b) o "Plano de Logística Sustentável no âmbito dos Tribunais de Justiça", com um direcionamento da análise das políticas públicas voltadas para o Poder Judiciário, com a veemência da imposição da implementação do PLS nos Tribunais; c) "A importância de políticas públicas sustentáveis para a sociedade" com a abordagem da axiologia do direito ao meio ambiente equilibrado, baseado na solidariedade, na justiça ambiental e na dignidade da pessoa humana.

Essa pesquisa bibliográfica foi responsável por concatenar as características do Plano de Logística Sustentável do Poder Judiciário - PLS/PJ aos basilares princípios do Estado de Direito Socioambiental, o que fez levar à conclusão de que o PLS/PJ é uma política pública inserida em uma gestão socioambiental responsável, preconizada pelo Estado de Direito Socioambiental, o qual é o instrumento eficaz para tornar o Poder Judiciário um modelo influenciador para a formação valorativa da sociedade pautada na justiça ambiental e na dignidade da pessoa humana, uma vez que há o incentivo do consumo consciente, revela aos servidores sobre a amplitude do conceito da eficiência de suas atividades laborais, o qual também está relacionada com a diminuição dos impactos ambientais, além de proporcionar a conscientização dos servidores sobre a necessidade de ser sustentável no âmbito do Estado de Direito Socioambiental.

Verifica-se que a relevância do presente trabalho se respalda justamente nesse estudo de quais são os valores que a população adquire ao visualizar a implementação de uma gestão sustentável no sistema judiciário. Além disso, esse estudo é importante por ser um estudo de um tema recente e de pouca discussão, pois a obrigatoriedade do Plano de Logística Sustentável nos Tribunais foi regulamentada apenas no ano de 2015, por meio da Resolução do Conselho Nacional de Justiça de nº 201. 


\section{ESTADO DE DIREITO SOCIOAMBIENTAL E A GESTÃO RESPONSÁVEL NO PODER PÚBLICO}

Para compreender as atividades governamentais é mister verificar que, de antemão, o Estado só existe pela própria existência da sociedade, teoria exaltada na obra do jus filósofo Hermann Heller. Essa verificação é de suma importância para o entendimento de que o governante só possui o poder no Estado de forma tênue e momentânea e de que os cidadãos possuem efetivamente a titularidade do poder do Estado. E ao longo da evolução histórica o Estado de Direito foi albergando direitos fundamentais como viés de sua atuação, sendo classificado da seguinte forma: a) o Estado Liberal, com os direitos de primeira geração relacionados à liberdade; b) o Estado de Bem-Estar Social, com os direitos de segunda geração, quais sejam, os direitos sociais; c) o Estado Socioambiental de Direito, pautado nos direitos difusos de terceira geração, com a representatividade da solidariedade e do direito ao meio ambiente ecologicamente equilibrado. Nota-se que a consecução dessa última forma estatal, a qual é a verificada contemporaneamente, está estritamente interligada a uma indissociabilidade da questão ambiental e social(CRUZ; FARIA; ITU, 2016).

SegundoWolkmer e Paulitsch (2013, p. 261), "o Estado de Direito Socioambiental, ancorado em uma ética ambiental, orienta-se sobre um pilar da sustentabilidade como baliza de sua ação e política, do qual a proteção ao meio ambiente emerge como uma das condições de legitimação de sua atuação". Essa mencionada ética transforma o Estado como paradigma de gestão voltada para um melhor gerenciamento da crise socioambiental a ser analisada de forma holística e para a promoção do desenvolvimento de uma sociedade mais participativa e reflexiva.Nesse âmbito, Saraiva e Véras Neto $(2015$, p. 357) afirmam ainda que a "construção de um Estado cujo valor axiológico - social e ambiental - esteja alicerçado no humano, como cidadão planetário, e na vida, como patrimônio comum da humanidade"é a legitimidade das políticas públicas ambientais.

Esse direcionamento da atividade do Estado ao público em geral, de modo indistinto e atemporal, com o intuito de proteger o meio ambiente e de garantir a existência digna das gerações presentes e futuras está alinhado ao pensamento de Kant, o qual afirma que o ser humano é analisado como fim em si mesmo, e não, como meio. E, assim, todas as ações em todas as esferas do governo devem estar condizentes às necessidades fins da população. $\mathrm{O}$ bem-estar do cidadão deve ser sempre 
o viés da funcionalidade do governo, pautado na dignidade da pessoa humana.A existência de um meio equilibrado alcançado por uma ação social e ambiental articulada e por um ordenamento jurídico que institucionaliza a proteção ambiental e confere um status de hierarquia fundamental dentre os direitos dos indivíduos são as características fundamentais do Estado de Direito Socioambiental.Tal hierarquia, inclusive, é positivada pela inserção do artigo 225 da Carta Magna, o qual disciplina que o poder público e a coletividade possuem o dever de defender e preservar o meio ambiente não somente para as gerações presentes, mas também, para as futuras. Além dessa imposição de uma relação equilibrada entre a ação humana e o meio ambiente, a Constituição Federal de 1988 também impõe a obrigatoriedade, em todas as esferas públicas, de desenvolver uma gestão socioambiental (CRUZ; FARIA; ITU, 2016; DADICO, 2011; ZURDO; GARDOLINSKI, 2016).

O estabelecimento na Administração Pública de uma gestão estratégica voltada para as questões ambientais levou ao aperfeiçoamento do planejamento sistemático e holístico da coordenação e do controle das ações e proporcionou uma atuação com resultados benéficos tanto para a seara estrutural dos órgãos e para questões político-econômicos quanto para a qualidade de vidas das pessoas.Percebe-se que essa gestão responsável do poder público atua em conformidade com os ditames constitucionais e com os princípios norteadores administrativos, sempre visando o interesse da coletividade. Assim, toda e qualquer prestação de serviço público deve se enquadrar em uma gestão socioambiental, a qual viabiliza uma melhor utilização dos recursos disponíveis e proporciona uma maior eficiência dos serviços oferecidos aos cidadãos com um menor impacto à natureza (MARQUES, 2012).

Esse respeito pelos interesses dos cidadãos, pelos direitos humanos, pelo Estado Democrático de Direito e pelo comportamento ético são algumas diretrizes encontradas na ISO 26000, a qual disciplina a responsabilidade socioambiental das instituições em suas decisões e em seus impactos gerados por sua atividade.Apesar dessa ISO ser voltada para o setor privado, suas diretrizes também atendem ao escopo de uma gestão responsável do setor público, afinal, se uma instituição analisa a questão socioambiental em seus processos decisórios, ela integra em sua organização o senso de responsabilidade social no sentido lato e pratica um desenvolvimento sustentável voltado para um comportamento ético (ZURDO; GARDOLINSKI, 2016). 
E quando se analisa na esfera governamental o principal programa responsável pela gestão socioambiental é a Agenda Ambiental na Administração Pública (A3P), oficializada pela Portaria $n^{0}$ 510/2002, e vinculada ao Ministério do Meio Ambiente. Essa Agenda estimula a mudança da cultura organizacional e da postura dos servidores, os quais ficam mais conscientes quanto ao uso dos recursos e à destinação dos resíduos gerados. A A3P combate ao desperdício e promove a qualidade do ambiente do trabalho, por meio da adoção dos 5R's, que representam repensar, recusar, reduzir, reaproveitar e reciclar, com a finalidade de incutir nos gestores a reflexão crítica sobre o consumismo e sobre a adequação do gerenciamento para evitar impactos negativos na natureza (ARAUJO; LUDEWIGS; CARMO, 2015; BARATA; KLIGERMAN; GOMEZ, 2007; MINISTÉRIO DO MEIO AMBIENTE, 2009).

Verifica-se também que, ao instituir um modelo de gestão socioambiental responsável, a entidade pública passa a ter melhores condições de planejar e direcionar suas decisões para a compatibilidade entre suas atividades e a preservação ambiental. E esse planejamento condizente com essa ótica mais solidária e humana, transforma-se num novo referencial de produção e consumo na esfera pública, principalmente quando o órgão público alcança os requisitos para obter uma certificação ambiental, pois conseguir um certificado ou uma premiação nessa seara transparece melhor as diretrizes de gestão responsável da instituição e transmite credibilidade àqueles que utilizam o serviço prestado, além de facilitar a adesão de todos os integrantes envolvidos (AZEVEDO, 2013; DADICO, 2011; TEIXEIRA,2013).

Essa gestão socioambiental responsável do poder público é condição sine qua non para a mudança comportamental de todos os colaboradores, inclusive, dos usuários cidadãos, o que leva à efetivação do direito constitucional a um meio ambiente ecologicamente equilibrado. Nesse sentido,

\footnotetext{
Cabe aos órgãos públicos a busca incessante na melhoria da prestação de serviços, vez que tem como público-alvo a Sociedade e, portanto, não lhes cabe a possibilidade de prestá-los com baixa ou mediana qualidade. Da mesma forma, a gestão de recursos públicos, sejam eles orçamentários, humanos, materiais ou de tempo, deve ser realizada de maneira enxuta e objetiva, impossibilitando o desperdício e a má utilização de um patrimônio que não pertence a uma entidade privada, mas à coletividade (ZURDO; GARDOLINSKI, 2016, p. 17)
} 
Ao adotar uma decisão ambientalmente correta e socialmente justa atende à necessidade finalística primária do Estado de promover o melhor para a sociedade. E evidentemente estabelecer a maximização de resultados com o mínimo de recursos é um dos meios para conquistar a eficiência da máquina pública. Esse princípio foi instituído pela Emenda Constitucional $\mathrm{n}^{\mathrm{o}} 19 / 98$ e, consequentemente, acrescido ao rol dos princípios administrativos presentes no caput do art. 37 da Constituição Federal de 1988. Juntamente com a legalidade (o administrador público em suas atividades funcionais está sujeito aos mandamentos da lei e às exigências do bem comum), moralidade (todo ato da Administração Pública deve ser condizente com a moral, boa-fé e o interesse público), impessoalidade (o administrador público só pode praticar um determinado ato para o seu fim legal) e publicidade (os atos devem ser divulgados oficialmente para o conhecimento público), a eficiência surge como um princípio imprescindível norteador das atividades do Estado e como dever do servidor de prestar com qualidade as suas atribuições. Percebe-se que não é suficiente que o administrador público atue apenas em conformidade com a lei, é essencial que o atendimento das necessidades dos cidadãos seja realizado de forma racional, transparente e da melhor qualidade, inclusive com a menor despesa e impacto ambiental possível. A premissa básica da eficiência é, portanto, a obtenção máxima de resultados com mínimo de recursos naturais, materiais, tecnológicos ou humanos. Buscar a eficiência no serviço público relaciona-se com a atualização, o alinhamento com a realidade, a dedicação na forma de atuar, a capacidade governamental de enfatizar na qualidade da execução. Afinal de contas, o objetivo do administrador público é garantir a satisfação dos cidadãos com os serviços prestados com qualidade, gerar mais benefícios à sociedade com os recursos disponíveis, direcionar a atividade à efetividade do bem comum de modo imparcial, neutro e transparente e incentivar a aproximação e participação da comunidade nos serviços públicos. (BOND, 2007; BRANCHIER; TESOLIN, 2007, MORAES, 2008).

Desse modo, atender aos princípios da ecoeficiência e da dignidade da pessoa humana por meio de uma gestão responsável é efetivar a função do Estado de Direito Socioambiental de se tornar paradigma ético para o comportamento da população e de promover a conscientizaçãode todos sobre a solidariedade e sobre a importância de obter uma visão holística no gerenciamento de suas atividades, para que estas sejam sempre voltadas para o interesse público e, consequentemente, para a proteção ambiental. 


\section{PLANO DE LOGÍSTICA SUSTENTÁVEL NO ÂMBITO DOS TRIBUNAIS DE JUSTIÇA}

É inegável a necessidade de todo o poder público estar envolvido na elaboração e efetivação de uma gestão socioambiental ativa e sólida em sua estrutura, e o Poder Judiciário não é diferente, uma vez que é integrante da estrutura do Estado de Direito Socioambiental. O Superior Tribunal de Justiça, por exemplo, adere a Agenda Ambiental da Administração Pública (A3P), a qual institui diversas medidas as quais consistem desde a eficiência energética da estrutura física do prédio público até a disponibilização de materiais para reciclagem. E quando se fala de macro gerenciamento dos órgãos judiciais, o Conselho Nacional de Justiça surge como subsídio norteador dos serviços prestados pelos Tribunais, pois atua em busca da padronização, aperfeiçoamento e controle das atividades do Poder Judiciário. A Recomendação de $n^{0} 11 / 2007$ foi de suma importância para o planejamento estratégico voltado para a sustentabilidade, pois incentivou diversas medidas, tais como a aquisição de materiais mais rentáveis ecologicamente e a disponibilização de materiais à reciclagem. Dispôs também sobre as políticas públicas voltadas para o desenvolvimento de um novo padrão de comportamento institucional, incluindo, a conscientização tanto dos servidores quanto dos jurisdicionados. Já no ano de 2010, o denominado CNJ instituiu a Meta Nacional $n^{\circ}$ 6, a qual reforçou sobre a necessidade de se preocupar com os impactos negativos causados pelas atividades laborais e estipulou a redução de, no mínimo, 2\% (dois por cento) do uso de combustível, energia, papel, água e telefone. E pautado no tripé da sustentabilidade, qual seja, ambientalmente correto, socialmente justo e economicamente viável, o Conselho Nacional de Justiça publicou a Resolução de $n^{\circ}$ 201/2015, momento em que não mais recomenda, e sim, impõe a obrigatoriedade de que todo Tribunal possua um Plano de Logística Sustentável, conhecido como PLS-PJ (DADICO, 2011; OLIVEIRA et al., 2014; ZURDO; GARDOLINSKI, 2016).

Nessa Resolução constam os requisitos (objetivos e responsabilidades definidas, ações, metas, prazos de execução, mecanismos de monitoramento e avaliação de resultados) e a estrutura necessária (como a criação de Núcleo Socioambiental) para a implementação desse Plano, além de apresentar os indicadores de controle (papel, copos descartáveis e água engarrafada, impressão de documentos e equipamentos instalados, energia elétrica, água e esgoto, gestão de resíduos, qualidade de vida no 
ambiente de trabalho, telefonia, vigilância, limpeza, combustível, veículos, layout e capacitação de servidores em educação ambiental). Há também sugestões de algumas boas práticas de gestão ambiental no Anexo II dessa Resolução, como: dar preferência ao uso de mensagens eletrônicas, digitalizar os documentos impressos, incentivar o uso do copo retornável, realizar campanhas de sensibilização e consumo consciente quanto ao uso da energia, adotar medidas para evitar o desperdício de água, promover a implantação da coleta seletiva, incentivar a adoção de práticas sustentáveis e colaborativas reconhecendo e premiando as unidades que possuem bons índices de consumo, utilizar preferencialmente combustíveis menos poluentes e de fontes renováveis como o etanol, implantação de tecnologia VoIP (Voice over Interne Protocol) - substituição de linhas analógicas por rede de dados e voz (ramais), descartar de forma ecologicamente correta os documentos e processos judiciais, incentivar ações de reutilização de materiais, estimular contratações sustentáveis, ou seja, com a inserção de critérios de sustentabilidade na especificação do objeto e controlar e monitorar os dados de consumo e informá-los às unidades de trabalho (CONSELHO NACIONAL DE JUSTIÇA, 2015).

Nota-se que essa Resolução além de tornar obrigatório esse instrumento de política pública ambiental denominado Plano de Logística Sustentável, ela trouxe uma uniformização na prática desse gerenciamento sustentável, determinando indicadores, os quais possibilitam a mensuração dos resultados obtidos, por meio das descrições dos objetivos, ações, metas, prazos de execução e o próprio monitoramento. A escolha desses detalhes deve ser cuidadosamente elencada pelo setor estratégico do Tribunal e deve ser continuamente acompanhada, pois as questões ambientais demanda uma constante vigilância dos gestores, para que a qualidade de vida nas diferentes gerações possa ser realidade.Isso só demonstra que não basta propor ações voltadas para a preservação ambiental, e sim, deve identificar se tais práticas sugeridas, de fato, surtem efeito positivo. Vislumbrar a eficiência das práticas sustentáveis é a comprovação de que a gestão daquele Tribunal é efetiva e sua mensuração oportuniza uma melhor análise de como maximizar a sustentabilidade no órgão público (BLÁZQUEZ; PERETTI, 2012; LIMA, 2004).

A sensibilização para questões socioambientais de todos os integrantes dos Tribunais desde os terceirizados até os magistrados é outro objetivo dos Planos de Logística Sustentável. De nada adianta estipular medidas sustentáveis se as pessoas envolvidas não possuem a consciência 
da responsabilidade social e ambiental de suas atitudes laborais e nem a capacitação para executar corretamente as ações propostas. Nessa conjuntura a educação ambiental dos profissionais se faz mister para desenvolver nas pessoas o amadurecimento da cidadania e o sentimento de pertencimento empoderado de que cada atitude individual surtirá efeito para a sociedade.O engajamento da causa ambiental verificado nos Tribunais de Justiça, principalmente, por meio dos Planos de Logística Sustentável demonstra aos usuários e aos funcionários o cumprimento do papel público de agir em conformidade com a sustentabilidade. $\mathrm{O}$ fato de dar exemplo de boas práticas ambientais e de conscientizar sobre o fato de que o direito constitucional ao meio ambiente equilibrado somente será efetivado com o esforço conjunto do Estado e da sociedade (OLIVEIRA et al., 2014; PONTES et al., 2015).

Assim, a tutela do meio ambiente é um dever sistemático e inafastável estatal e os órgãos do Poder Judiciário simbolizam os valores preconizados pelo Estado de Direito Socioambiental e estes devem servir de modelo de sustentabilidade. E por este motivo essas ações presentes no PLS também envolvem a questão estrutural dos prédios, para que reflitam a excelência do gerenciamento dos recursos públicos e transmitam a imagem de sustentabilidade.Um exemplo emblemático da gestão sustentável dos Tribunais foi a instituição dos processos eletrônicos, pois essa ação além de ter proporcionado a celeridade processual, reduziu de forma drástica a quantidade de resmas utilizadas, otimizou o espaço físico do trabalho, diminuiu o deslocamento físico das partes envolvidas nos processos e, consequentemente, diminuiu as emissões de $\mathrm{CO}_{2}$ (DADICO, 2011; GONÇALVES, 2017).

É inegável que ao analisar os efeitos de uma ação percebe-se que são concatenados e interdependentes, e se uma atividade não for bem planejada sob a ótica sistêmica dos fatores envolvidos, as consequências podem ser catastróficas, essencialmente, no mérito ambiental. É essa fragilidade do meio ambiente que traz, desde a Conferência de Estocolmo de 1972, a característica do "esverdeamento" do ordenamento jurídico e a justificativa plausível de modificar a estrutura física, humana e econômica dos órgãos judiciários para se adaptar ao conceito sustentável(BENJAMIN, 2011).

Os PLS-PJ, instrumentos da política pública socioambiental dos Tribunais, passaram a ser multiplicadores de boas práticas de gestão pública e a sensibilizar os envolvidos sobre a importância do fortalecimento 
da sustentabilidade. O judiciário brasileiro com a implementação desse plano de logística adquire uma missão maior do que fazer justiça social nos julgamentos dos processos, transcende a uma vertente de justiça, denominada de justiça ambiental, na qual cada um possui o direito de obter um meio ambiente ecologicamente equilibrado pautado no reconhecimento dos valores transcendentes, universais e intrínsecos da natureza e na relação existencialista entre o homem e o meio ambiente (ARANTES; VIEIRA NETO; CARDOSO, 2014; FLORIT, 2016; ZANGALLI JUNIOR, 2013).

Portanto, o Plano de Logística Sustentável do Poder Judiciário, implementado pelo Conselho Nacional de Justiça em 2015, representa um instrumento referencial dos valores instituídos no Estado de Direito Socioambiental, dos quais a sustentabilidade é a força motriz das políticas públicas. O desenvolvimento dessa gestão responsável eficiente comprometida com a mudança constante e evolutiva da estrutura física e humana sensibiliza os funcionários e os usuários a consumir conscientemente e efetiva o cumprimento da obrigação constitucional de defender e preservar o meio ambiente.

\section{A IMPORTÂNCIA DE POLÍTICAS PÚBLICAS SUSTENTÁVEIS PARA A SOCIEDADE}

As atuações governamentais influenciam direta e indiretamente a vida de cada indivíduo e por esse motivo a implementação das ações sustentáveis na esfera pública é um interesse da sociedade como um todo e é uminstrumento de promoção da preservação do meio ambiente, contribuindo para a garantia constitucional do artigo 225, da Constituição Federal de 1988. A axiologia desse direito, por sua vez, adquire outra dimensão maior do que simplesmente um direito fundamental constitucionalizado, pois assume uma carga valorativa de direito humano pelo fato de a relação intrínseca entre o equilíbrio ecológico do meio ambiente e a qualidade de vida possuir um caráter extensivo do direito à vida. É, portanto, um direito transcendente que diz respeito a todos indistintamente e assegurar essa proteção ambiental é justamente conferir eficácia ao princípio da dignidade da pessoa humana e, consequentemente, garantir a existência do próprio ser humano (MARQUES, 2012; MORAES, 2016; RANGEL, 2014; STEFANELLO, 2010).

A institucionalização do desenvolvimento sustentável traduz o agir de uma sociedade que consolidou no ordenamento jurídico a noção 
da imprescindibilidade da qualidade do meio ambiente para a efetivação da dignidade do desenvolvimento humano, com base sólida no art. $1^{\circ}$, inciso III, da Constituição Federal, concernente ao princípio da dignidade da pessoa humana, e no art. $3^{\circ}$, inciso I, dessa mesma legislação referente à construção de uma sociedade livre, justa e solidária. Essa solidariedade, inserida nos direitos da terceira geração, diz respeito à dicotomia existente entre a sociedade e o Estado, pois a consecução de um meio ambiente sadio e equilibrado é alcançada pela ação conjunta entre esses dois atores e essa união fortalece a sustentabilidade e a justiça ambiental(CRUZ; FARIA; ITU, 2016; RAMMÊ, 2013; RIBAS, 2016; SILVA, 2011).

A persecução da sustentabilidade é uma tarefa árdua para a gestão pública, pelo fato de envolver diversos fatores e valores no momento decisório da ação. Atuar de forma sustentável é uma tarefa complexa a qual persiste ao longo do tempo, pois consiste em aliar a continuidade do desenvolvimento social, político e econômico do Estado sem prejudicar a qualidade de vida da geração futura (FOLADORI; TOMMASINO, 2000; RIBEIRO, 2017; SCHULZA, 2015).

Então, além de balizar as políticas públicas sobre o viés do alcance da dignidade da pessoa humana e da solidariedade, o alcance da justiça também está incluído nesse contexto. Para Hans Kelsen, ser justo é garantir a felicidade das pessoas e na seara ambiental significa aliar a harmonia social com a manutenção da vida saudável para proporcional o bem-estar da coletividade. Verifica-se, assim, a construção de uma cidadania alicerçada no ambientalismo, na qual os indivíduos adquirem a capacidade de refletir criticamente sobre as causas e os efeitos de suas ações e analisam as melhores escolhas condizentes com a diminuição dos impactos negativos na natureza e na harmonização da sociedade(LIMA, 2004; LIMA, 2009; SARAIVA; VÉRAS NETO, 2012).

O consumo exacerbado e o desleixo na destinação final dos produtos são substituídos pela análise criteriosa do que é mais vantajoso para a sociedade, para o meio ambiente e para a economia concomitantemente. A realização desse sopesamento aliado ao abandono dos modelos de esgotamento de recursos naturais e ao desenvolvimento de novas concepções e práticas de atitudes cotidianas são os desafios de todos os integrantes da sociedade e do governo. E a Administração Pública como representa o Estado, essa deve atender à coletividade, com ações que proporcionem o bem comum e a sustentabilidade. As políticas públicas sustentáveis são, portanto, ferramentas indispensáveis para a garantia 
da proteção tanto do meio em que as pessoas estão inseridas quanto da vida destas, uma vez que o ser humano é indissociável da natureza e os impactos ocorridos ao meio ambiente atingem os indivíduos de forma direta ou indiretamente. E a existência de pilares sólidos de planejamento estratégico, de reestruturação das políticas e de mudanças de paradigmas voltados para a minimização desses impactos é uma forma, inclusive, de incutir nos próprios servidores a responsabilidade de cada um enquanto ser social e cidadão para agir em prol à coletividade.

Essa gestão do uso racional dos recursos ambientais acompanha a tendência de integrar a escolha racional das diretrizes sustentáveis com o uso eficiente de todos os recursos desde o material até o humano.E ao decidir por uma determinada ação ele está atribuindo a essa escolha um valor moral, o qual traz à sustentabilidade a sua tutela primordial. Elencar quais as medidas a serem executadas em uma instituição está estritamente relacionada à busca de uma melhor eficiência do gasto público e da gestão dos processos de trabalho aliado a um acompanhamento contínuo de ações de qualidade, sustentabilidade e racionalização. E essa é a função maior de uma política pública, qual seja, promover, em prol do interesse público, o meio ambiente sadio e ecologicamente equilibrado (DESLATTE, 2015; MARIN; SILVA, 2013; MARQUES, 2012; OLIVEIRA; GADELHA, 2014).

Nesse sentido, os gestores dos Tribunais, direcionados pela normatização do Conselho Nacional de Justiça,assumem essa responsabilidade socioambiental de possuir uma administração e uma política estratégica direcionada para adaptação dos serviços à questão do meio ambiente. Dentre os programas de ações estatais no Poder Judiciário percebe-se que o Plano de Logística Sustentável é o instrumento representativo do esforço do Estado de incutir em sua estrutura parâmetros razoáveis de sustentabilidade. Há um encadeamento dos requisitos para cumprir com essa gestão, fortalecendo a sistemática do planejamento e o controle dos resultados obtidos. Por meio do PLS-PJ, os Tribunais proporcionaram com mais veemência a prática de medidas ajustadas ao uso racional dos recursos e estabeleceram como cultura organizacional a conscientização ambiental.

E quando um cidadão verifica as práticas sustentáveis adotadas pelos órgãos públicos, ele enxerga a imagem dos próprios valores da sociedade na qual está inserido. Se um Tribunal se preocupa em diminuir, por exemplo, o quantitativo de resma de papel utilizado, o indivíduo, 
seja funcionário ou usuário daquele sistema, irá inevitavelmente utilizar como parâmetro esse exemplo para suas próprias decisões. Torna-se uma reprodução automática de uma mudança comportamental e um despertar pela educação ambiental.

Desse modo, como a intervenção na natureza é inevitável, o que se deve almejar é uma relação entre a eficiência do setor público e a otimização de um meio ambiente ecologicamente equilibrado. Esse é o resultado de maior valorização para a sociedade contemporânea, o mínimo possível de deterioração e/ou interferência no meio ambiente. A axiologia do Plano de Logística Sustentável no âmbito do Poder Judiciário está alicerçada no desenvolvimento da cidadania socioambiental, na concretização da justiça ambiental e da solidariedade e na garantia da dignidade da pessoa humana. Em suma, as políticas públicas socioambientais representam a garantia da continuidade da existência humana em condições cada vez mais dignas e justas.

\section{CONCLUSÕES}

Percebe-se que a sociedade atual está inserida no Estado de Direito Socioambiental, cuja característica fundamental é a consciência jurídica da coletividade pautada na preservação do meio ambiente. Nesse âmbito o objetivo é proteger a natureza de forma holística, com ações voltadas para a garantia da existência digna das pessoas do presente e do futuro, além de assegurar a permanência do elo entre o cidadão e o meio em que vive.

A gestão socioambiental incutida na Administração Pública assume um papel relevante para agregar essa reflexão de atenuar a utilização dos recursos naturais, de desenvolver novas medidas mais eficientes e de proporcionar serviços com melhor qualidade, tudo sob o escopo constitucional de estabelecer uma relação humana equilibrada e sadia com o meio ambiente. Foi mencionado nesse trabalho, inclusive, a Agenda Ambiental na Administração Pública (A3P) como exemplo de programa administrativo e estratégico responsável por assessorar os órgãos públicos em sua reestruturação das prestações de serviços oferecidos à população. Essas políticas públicas se tornam paradigmas de comportamento social e indicam qual o conteúdo axiológico que o Estado, por meio de sua estrutura governamental, permeia em suas atividades.

E essa tentativa de alcançar a excelência da relação entre o serviço público e a preservação ambiental fez com que o Conselho Nacional 
de Justiça publicasse, dentre outros normativos, a Recomendação de $\mathrm{n}^{\circ}$ 11/2007, a Meta Nacional no 6/2010 e a Resolução de no 201/2015, sendo esta última a mais importante pelo seu caráter imperativo de um Plano de Logística Sustentável no âmbito do Poder Judiciário. Foi comentando ao logo desse artigo que os Tribunais ao cumprir essa Resolução passaram a adotar objetivos, metas, ações e monitoramento dos resultados de uma forma diferenciada e mais engajada com a questão do meio ambiente.

Verificar um gerenciamento de um órgão do Tribunal voltado para medidas sustentáveis significa para a sociedade a capacidade de o Estado pensar e agir em prol da coletividade, incutindo nos cidadãos a ideia de que cada ação humana gera uma consequência na natureza, cujo efeito é de responsabilidade solidária de todos. Educar, conscientizar e monitorar a atividade de um profissional em seu ambiente de trabalho é garantir de que sua atitude não seja danosa a outrem, inclusive em caráter ambiental. E, assim, a gestão pública moderna apresenta a característica não somente de desburocratização dos serviços, mas também de uma administração eficiente na utilização dos recursos ambientais, materiais, sociais, financeiros e humanos.Anecessidade de coexistência do ser humano e da natureza faz com que a questão ambiental seja vista como um direito fundamental e um direito humano, com uma carga valorativa de garantir além da qualidade de vida dos cidadãos, de oportunizar a permanência da vida dos próprios indivíduos.

Assim, o objetivo desse presente trabalho de relacionar as diretrizes do Estado de Direito Socioambiental e as políticas públicas sustentáveis do Poder Judiciário com a importância valorativa de tais medidas de sustentabilidade para apopulação foi alcançado pela análise da teleologia das atividades públicas, voltadas para a própria sociedade; pela abordagem dos princípios do Estado Socioambiental, de dignidade da pessoa humana, solidariedade e justiça ambiental; e pela busca da ecoeficiência do PLS-PJ. E pelo fato de a obrigatoriedade do Plano de Logística Sustentável nos Tribunais ter sido regulamentada recentemente no ano de 2015, por meio da Resolução do Conselho Nacional de Justiça de $n^{\circ} 201$, esse trabalho possui uma grande importância para subsidiar futuras discussões teóricas sobre o referido tema e para conscientizar os cidadãos sobre a relevância de uma gestão pública voltada para a preservação do meio ambiente.

E por esse motivo o presente artigo conclui que o Plano de Logística Sustentável é uma política pública inserida em uma gestão socioambiental responsável, preconizada pelo Estado de Direito Socioambiental, e é 
um modelo orientador moral para a sociedade em suas ações cotidianas, pautado na justiça ambiental e na dignidade da pessoa humana. Tal medida sustentável adotada pelo Poder Judiciário estimula ações as quais alicerçam os ideais da sustentabilidade e promove a efetivação do direito ao meio ambiente ecologicamente equilibrado, alicerçando princípios axiológicos do Estado de Direito Socioambiental fundamentais para a construção de uma Justiça mais socialmente responsável e para a garantia da qualidade de vida dos cidadãos e da permanência digna da própria vida dos seres humanos.

\section{REFERÊNCIAS}

ARANTES, Rafael Setúbal; VIEIRA NETO, Ana Maria; CARDOSO, Jhéssica Ribeiro. Planos de Gestão de Logística Sustentável: ferramenta para boas práticas na gestão pública. In: Congresso CONSAD de Gestão Pública, n. 7, 2014, Brasília. Disponível em: <http://banco.consad.org.br/ handle/123456789/1149>.Acesso em: 13 jun. 2017.

ARAUJO, Carolina Lopes; LUDEWIGS, Thomas; CARMO, Almeida do. A Agenda Ambiental na Administração Pública: desafios operacionais e estratégicos. Desenvolvimento em Questão, v. 13, n. 32, out./dez. 2015. Disponível em: <http://www.redalyc.org/articulo.oa?id= 75241745003> Acesso em: 23 out. 2017

BARATA, Martha M. de L.; KLIGERMAN, Débora C.; GOMEZ, Carlos M. Gestão ambiental no setor público: uma questão de relevância social e econômica. Revista Ciência e Saúde Coletiva, Rio de Janeiro, v. 12, n. 1, jan./mar. 2007. Disponível em: <http://www.scielosp.org/scielo. php?script=sci_arttext\&pid=S1413-81232007000100019>. Acesso em: 27 fev. 2017.

BENJAMIN, Antonio Herman. Estado de direito socioambiental. 2011. Revista dos Tribunais, 2011. Disponível em: <http://bdjur.stj.jus.br/jspui/ handle/2011/40556> . Acesso em: 05 maio 2017.

BLÁZQUEZ, Miguel; PERETTI, María Florencia. Modelo para gestionarlasustentabilidad de lasorganizaciones a través de larentabilidad, adaptabilidad e imagen. EstudosGerenciales -Journal of Management and Economics for Iberoamerica, v. 28, n. 125, out./dez. 2012. Disponível em: $<$ https://www.icesi.edu.co/revistas/index.php/estudios_gerenciales/article/ view/1527/html>. Acesso em: 25 fev. 2017.

CAlgARO, Cleide; PEREIRA, Agostinho OliKoppe. Políticas Públicas 
e Cooperação Social em John Rawls. Revista Veredas do Direito: Direito Ambiental e Desenvolvimento Sustentável, Belo Horizonte, v. 14, n. 28, p. 277-302, jan./abr. 2017.Disponível em: <http://www.domhelder.edu.br/ revista/index.php/veredas/article/view/970>.Acesso em: 21 out. 2017.

BOND, Maria Thereza. Práticas profissionais na gestão pública. 1.ed. Curitiba: Ibpex, 2007.

BRANCHIER, Alex Sander; TESOLIN, Juliana Daher Delfino. Direito e legislação aplicada. 3.ed. Curitiba: Ibpex, 2007.

CONSELHO NACIONAL DE JUSTIÇA. Resolução n. 201, de 03 de março de 2015. Dispõe sobre a criação e competências das unidades ou núcleos socioambientais nos órgãos e conselhos do Poder Judiciário e implantação do respectivo Plano de Logística Sustentável (PLSPJ), Brasília, DF, 2015.

CRUZ, Paulo Marcio; FARIA, Daniela L. de; ITU, Christian N. A necessária evolução do Estado de Direito Social teorizado por Herman Heller ao Estado de Direito Socioambiental diante da crise ambiental na sociedade de riscos.Revista Brasileira de Direito, v. 12, n. 1, p. 7487, jan./jun. 2016. Disponível em: <https://seer.imed.edu.br/index.php/ revistadedireito/article/view/1119>. Acesso em: 27 fev. 2017.

DADICO, Claudia Maria. Levando a gestão ambiental a sério: A relevância da Certificação ISO 14001 das unidades da $4^{a}$ Região da Justiça Federal como instrumento de gestão ambiental. Revista de Doutrina da $4^{a}$ Região, n. 42, jun. 2011. Disponível em: <http://bdjur.stj.jus.br/jspui/ handle/2011/41655>. Acessoem: 27 fev. 2017.

DESLATTE, Aaron. Reassessing "City Limits" in Urban Public Policy. PSJ - PolicyStudiesJournal, v. 43, p. 56-77, mar. 2015. Disponível em: $<$ http://onlinelibrary.wiley.com/ doi/10.1111/psj.12102/abstract $>$. Acesso em: 01 mar. 2017.

FLORIT, Luciano Félix. Conflitos ambientais, desenvolvimento no território e conflitos de valoração: considerações para uma ética ambiental com equidade social. Revista Desenvolvimento e Meio Ambiente, v. 36, p. 255-271, abr. 2016. Disponível em: <http://revistas.ufpr.br/made/article/ view/41624>.Acesso em: 12 maio 2017.

FOLADORI, Guillermo; TOMMASINO, Humberto. El concepto de desarrollosustentabletreintaañosdespués. Revista Desenvolvimento e Meio Ambiente, v. 1, p. 41-56, jan./jun. 2000. Disponível em: <http://revistas. ufpr.br/made/article/view/3056>.Acesso em: 19 maio 2017.

GONÇALVES, Mariana Berardinelli Vieira Braz. Função Socioambiental 
da Propriedade como corolário do Estado socioambiental democrático de direito brasileiro. Revista Direito Ambiental e Sociedade, v. 7, n. 1, p. 89-119, 2017. Disponível em:<http://www.ucs.br/etc/revistas/index.php/ direitoambiental/article/view/4865>. Acesso em: 04 jun. 2017.

LIMA, Cristina de Araújo. Multiespacialidades metropolitanas e construção social do lugar rumos para a sustentabilidade. Revista Desenvolvimento e Meio Ambiente, v. 9, p. 39-56, jan./jun. 2004. Disponível em: <http:// revistas.ufpr.br/made/article/view/3080>. Acesso em: 19 maio 2017.

LIMA, Gustavo Ferreira da Costa. Educação, sustentabilidade e democracia: explicitando a diversidade de projetos político-pedagógicos. Revista Desenvolvimento e Meio Ambiente, v. 20, p. 69-75, jul./dez. 2009. Disponível em: <http://revistas.ufpr.br/made/article/view/15181>.Acesso em: 19 maio 2017.

MARIN; Jeferson Dytz; SILVA; Mateus L. da. Limites e Possibilidades da Decisão em Matéria Ambiental. Sequência: Estudos Jurídicos e Políticos, Florianópolis, n. 67, p. 223-249, dez. 2013. Disponível em: <http://www. scielo.br/scielo.php?pid=S2177-70552013000200009\& script=sci abstract\&tlng=pt $>$. Acesso em: 01 mar. 2017.

MARQUES, Carlos Alexandre M. A nova função do Poder Judiciário na 'sindicância' do mérito administrativo em matéria ambiental. Medio Ambiente \&Derecho, Revista electrónica de derecho ambiental, n. 23, jul. 2012. Disponível em: <http://libros-revistas-derecho.vlex.es/vid/judiciario-ncia-rito-mata-ria-ambiental-459191854> . Acessoem: 25 fev. 2017.

MCINTYRE-MILLS, Janet. et al. How can we break the mould? Democracy, semiotics and regional governance. Systems Research and Behavioral Science, v. 25, p. 305-321, 2008. Disponívelem: <http://onlinelibrary. wiley.com/doi/10.1002/sres.888/abstract>. Acesso em: 01 mar. 2017.

MINISTÉRIO DO MEIO AMBIENTE. Brasília, Agenda Ambiental na Administração Pública. Brasília, DF, 5 ed.2009

MORAES, Alexandre de. Direito constitucional. 32. ed. São Paulo: Atlas, 2016.

OLIVEIRA, Ivan de; GADELHA, Francisco Ernane Abreu. A gestão 
ambiental e a análise do uso racional e ecologicamente correto dos recursos naturais e seus processos no centro de tecnologia da Universidade Federal do Ceará. Revista do Centro do Ciências Naturais e Exatas - UFSM, Santa Maria, v. 18, n. 1, p. 43-56, abr. 2014. Disponível em: <https://periodicos. ufsm.br/reget/article/view/10324>. Acesso em: 25 fev. 2017.

OLIVEIRA, Leonel G. L. et al. A gestão ambiental no Poder Judiciário: estudo exploratório de um Tribunal de Justiça. REUNIR: Revista de Administração, Contabilidade e Sustentabilidade, v. 4, p. 113-133, 2014. Disponível em: $<$ http://revistas.ufcg.edu.br/reunir/index.php/uacc/ article/ view/208/pdf>. Acesso em: 25 fev. 2017.

PONTES, Andréa S. M. et al. Sustentabilidade e educação superior: análise das ações de sustentabilidade de duas instituições de ensino superior de Santa Catarina. Revista de Administração da UFSM, Santa Maria, v. 8, p. 84-103, 2015. Disponível em: <https://periodicos.ufsm. br/reaufsm/article/ view/16298/pdf>. Acesso em: 25 fev. 2017.

RAMMÊ, Rogério Santos. Federalismo Ambiental Cooperativo e Mínimo Existencial Socioambiental: a Multidimensionalidade do Bem-Estar Como Fio Condutor. Revista Veredas do Direito: Direito Ambiental e Desenvolvimentos Sustentável, Belo Horizonte, v. 10, n. 20, jul./dez. 2013. Disponível em: <http://domhelder.edu.br/revista/index.php/veredas/ article/view/380>. Acesso em: 05 maio 2017.

RANGEL, Tauã Lima Verdan. A Construção do Estado de Direito Socioambiental a partir da ótica Habermasiana: a consolidação do mínimo existencial socioambiental como elemento de afirmação da dignidade da pessoa humana. Revista Veredas do Direito: Direito Ambiental e Desenvolvimentos Sustentável, Belo Horizonte,v. 11, n. 21, p. 135-161, jan./jun. 2014. Disponível em: <http://domhelder.edu.br/revista/index. php/veredas/article/view/371>.Acesso em: 05 maio 2017.

RIBAS, Giovanna Paola Primor. O tratamento jurídico dos recursos hídricos no Brasil e nos Estados Unidos da América. Revista Veredas do Direito: Direito Ambiental e Desenvolvimentos Sustentável, Belo Horizonte, v. 13, n. 27, 2016. Disponível em: <http://www.domhelder.edu.br/revista/index. php/veredas/article/view/ 838>.Acesso em: 08 maio 2017.

RIBEIRO, Fernando Pinto. O paradigma ambiental na globalização 
neoliberal: da condição crítica ao protagonismo de mercado. Revista Sociedade \& Natureza, Uberlândia, v. 24, n. 2, p. 211-226, 2012. Disponível em: <http://www.seer.ufu.br/index.php/sociedadenatureza/ article/view/14819>.Acesso em: 12 maio 2017.

SARAIVA, Bruno Cozza; VERAS NETO, Francisco Quintanilha. A justiça socioambiental como fundamento contra-hegemônico à globalização e à mercadorização ambiental. Medio Ambiente \&Derecho, Revista electrónica de derecho ambiental, n. 23, jul. 2012. Disponível em: <http:// libros-revistas-derecho.vlex.es/vid/socioambiental-fundamento-nicoambiental-459191774>. Acesso em: 25 fev. 2017.

SARAIVA, Bruno Cozza; VERAS NETO, Francisco Quintanilha. Estado, Constituição e Globalização: a Retomada do Social e a Construção do Ambiental. Revista Veredas do Direito: Direito Ambiental e Desenvolvimentos Sustentável, Belo Horizonte, v. 12, n. 23, p. 337-366, jan./jun. 2015. Disponível em: <http://www.domhelder.edu.br/revista/ index.php/veredas/article/view/572/451>. Acessoem: 21 out. 2017.

SCHULZA, Jule. et al. Design, implementation and test of a serious online game for exploring complex relationships of sustainable land management and human well-being. Systems Environmental Modelling \& Software, v. 65, p. 58-66, mar. 2015. Disponívelem: <http://www.sciencedirect.com/ science/article/pii/S1364815214003557?np=y\&npKey=77c798cb64bf8e 3ec7b0a78adb36f8744fcfc256e9856d42e5c7fcda96b471b7>. Acesso em: 01 mar. 2017.

SILVA, Marcela Vitoriano e. O princípio da solidariedade intergeracional: um olhar do Direito para o futuro. Revista Veredas do Direito: Direito Ambiental e Desenvolvimentos Sustentável, Belo Horizonte, v. 8, n. 16, p. 115-146, jul./dez.2011. Disponível em: <http://domhelder.edu.br/revista/ index.php/veredas/article/view/179>.Acesso em: 07 maio 2017.

STEFANELLO, Alaim Giovani Fortes. Diálogos entre Direitos Humanos Sociobiodiversidade e propriedade intelectual. Revista Veredas do Direito: Direito Ambiental e Desenvolvimento Sustentável, Belo Horizonte, v. 7, n. 13/14, p. 27-56, jan./dez. 2010. Disponível em: <http://www.domhelder. edu.br/revista/index.php/veredas/ article/view/23>.Acesso em: 08 maio 2017.

TEIXEIRA, Maria Gracinda C.; AZEVEDO, Luís P. A Agenda Ambiental Pública: barreiras para a articulação entre critérios de sustentabilidade e as novas diretrizes da administração pública federal brasileira. Revista 
Eletrônica de Administração - REAd, Porto Alegre, ed. 74, n. 1, p. 139164, jan./abr. 2013. Disponível em: <http://www.seer.ufrgs.br/read/article/ view/ 33063>. Acesso em: 27 fev. 2017.

WOLKMER, Maria de Fátima Schumacher; PAULITSCH, Nicole da Silva. O Estado de Direito Socioambiental e a Governança Ambiental: ponderações acerca da judicialização das políticas públicas ambientais e da atuação do Poder Judiciário. Revista Novos Estudos Jurídicos - NEJ Eletrônica, v. 18, n. 2, p. 256-268, maio/ago. 2013,Disponível em: <http:// siaiap32.univali.br/seer/index.php/nej/ article/view /4678>. Acesso em: 05 maio 2017.

ZANGALLI JUNIOR, Paulo Cesar. Sustentabilidade urbana e as certificações ambientais na construção civil. Revista Sociedade \& Natureza, Uberlândia, v. 25, n. 2, p. 291-302, maio/ago.2013. Disponível em: <http:// www.seer.ufu.br/index.php/sociedadenatureza/article/view/19639>. Acesso em: 12 maio 2017.

ZURDO, AureteNicolodi; GARDOLINSKI, Maria Terezinha HanelAntoniazzi. Implantação de política socioambiental em órgão judiciário trabalhista. Revista Caderno Gestão Pública, v. 8, n. 5, 2016. Disponível em: <https://www.uninter.com/cadernosuninter/index.php/ gestao-publica/article/view/506>.Acesso em: 19 maio 2017.

Recebido em: 18/01/2018. Artigo aceito em: 09/05/2018.

\section{Como citar este artigo (ABNT):}

LEÃO, Bárbara de Castro; MELO, Daniele de Castro Pessoa de. A AXIOLOGIA DO PLANO DE LOGÍSTICA SUSTENTÁVEL DOS TRIBUNAIS PARA A SOCIEDADE. Veredas do Direito, Belo Horizonte, v. 15 , n. 31 , p. 247-269, jan./abr. 2018. Disponível em: <http://www. domhelder.edu.br/revista/index.php/veredas/article/view/1231>. Acesso em: dia mês. ano. 